\title{
A Design and Study on the Framework of University Academic Atmosphere Governance Based on IT Governance Theory
}

\author{
Zhao Huan $^{\mathrm{a}, 1}$, Song Qiang ${ }^{\mathrm{a}}$, Duo Zhen ${ }^{\mathrm{a}}$ and Zheng Biyi ${ }^{\mathrm{a}}$ \\ ${ }^{a}$ Network and Information Center (Library), Beijing International studies University, \\ Beijing, China
}

\begin{abstract}
Information technology profoundly affects both the teaching and the scientific research activities of the universities and determines their core competitiveness. In recent years, the academic atmosphere construction in universities has increasingly resulted in exposing large number of management problems. Therefore, the application of IT governance is perhaps the only way for the development of informationization in the universities. This paper attempts to integrate IT governance theory into academic atmosphere construction, in a controlled state, by avoiding various risks in the construction process and finally, accomplishes the purpose of informationization construction leading to the reforms in university education system.
\end{abstract}

Keywords. Information technology; IT governance; academic atmosphere construction

\section{Introduction}

The academic atmosphere construction is the core content which paves a way for all the universities to implement the quality education projects. The rapid developments in modern society put forth higher demands on the comprehensive ability and overall quality of the talents. The systematic research in university academic atmosphere construction helps academic community to grasp the characteristics, understand its connotation and thus, provide a theoretical foundation for the establishment of work elements in setting the target system. In addition, it significantly promotes its all-round development through long-term mechanism in achieving good educational effects.

Steven Farr [1] believes that by establishing a new education system, reducing the impact of the family's socioeconomic background, establishing the idea of changing fate by improving grades and providing learning guidance and financial support in school can build good academic atmosphere. Wang Enjuan[2] believes that academic atmosphere assessment includes students' attitude towards learning, integrity condition, and management of students in the universities. According to Zhang Diping[3] the students' quality, teachers' teaching abilities and overall academic atmosphere are the

${ }^{1}$ Zhao Huan, Network and Information Center (Library), Beijing International studies University, Beijing, China; E-mail: zhaohuan@bisu.edu.cn. 
key evaluation indicators of any academia. Students' qualities include learning status, after-school arrangements and student management. Teachers' teaching includes class management, class teaching and students' learning status. The academic atmosphere includes regulations, degree of influences, and academic atmosphere activities. Whereas, Zong Hongyu[4] trusts that school's security system, teacher's teaching and students' learning are the key academic atmosphere indicators. School's security system comprises of human, material and management security while, teachers' teaching includes the teaching staff and the results of teaching.

Academic atmosphere governance has become one of the most important link in teaching quality monitoring system in the universities. Its governance efficiency greatly affects or even determines the overall level of the university. However, the detailed study of traditional governance reveals that its evaluation methods are relatively simple. The usual way is to calculate the weighted average score based on the teacher's evaluation score of each teaching class, and then simply rank with class as a unit according to the score. Hui Zhibing[5] believes that each student possesses distinct own characteristics, and the construction of class style should be taken as a unit, strengthen the construction and guidance of class style, and enhance students' sense of collective honor. The advantage of building class style is mainly, the students in the class. They are of the same major, and can be guided by the class style according to the characteristics of each major. The ranking order of the class is however, the sole basis for assessment of academic atmosphere. Although this assessment method has certain effectiveness, it also has obvious shortcomings and is mainly reflected in the inability to accurately distinguish among classes with outstanding academic performance, ordinary performance, and poor performance. Therefore, it is impossible to formulate and implement targeted governance programs based on the characteristics of each group. This hampers the effect of academic atmosphere governance to a certain extent, and its value in helping to improve university's academic atmosphere is also very limited. The reference value is not high. However, in today's data era, the idea of datadriven decision-making has gradually become a mainstream. Starting from the actual needs of university academic management, based on the application and function realization of data science-related technologies, it is necessary to explore and formulate a set of programs that can effectively improve the efficiency of academic atmosphere governance.

The domestic and foreign researchers show different characteristics on the academic atmosphere construction in various universities. The study of foreign scholars mainly emanates from the perspectives of academic integrity, academic misconduct, academic cheating, etc., and has a great reference value for the study in China. The domestic research focuses on the theoretical research and construction of evaluation index system, and conducts empirical research in combination with the evaluation methods. The academic atmosphere is mainly based on the colleges and universities, teachers and students. In a broad sense, the academic atmosphere includes the style of colleges and universities, the teaching style of teachers and the academic atmosphere of students. There are generally two types of academic governance requirements in colleges and universities: one is an annual long-term plan, and the other can be seen as a temporary special operation. But no matter what kind of demand it is, it can be completed under IT governance. The governance process generally includes five parts: governance planning, governance initiation, implementation and control, governance maintenance, and governance performance. Since the formation and development of the academic atmosphere in the colleges and universities is not just completed by an individual, but 
by the individuals in the groups and inter-group interactions. The construction and formation of the academic atmosphere is a group or organizational behavior, so the governance of academic atmosphere can be regarded as a systematic project.

\section{Theoretical Researches of University Academic Atmosphere Governance Based on IT Governance}

At present, colleges and universities have paid attention to the construction of academic style from the top-level design. YU Chang[6] used the construction of schools, departments, and classes, as well as the microcosmic students' personal growth goals, to study the main factors affecting the current style of study construction from three levels and perspectives, so as to develop a theoretical framework for the construction of academic atmosphere. Through the profound implementation of the concept of "three holistic education", Hou Yajie[7] conceptualized the school's allemployee collaborative education model to stimulate students' interest in learning, to create a positive style of study, and design guidance and implementation methods for the construction of college style of study in order to realize the collaborative education of all the school staff. From the point of view of the problems of emphasis on evaluation and neglect of governance in the style of study in colleges and universities, we propose a theoretical and logical interpretation of the problems in the process from three perspectives: macro, meso and micro in a more comprehensive, precise and standardized manner.

\subsection{Characteristics of University Academic Atmosphere Governance Based on IT Governance Theory}

The theory and practice of IT governance need to run through the entire life cycle of the academic atmosphere governance management and accurately relate to its dayto-day management. In view of the inherent differences among the universities, the application of university IT governance in academic atmosphere governance is divided into following three characteristics:

Top-level Promotion: As the executors of specific policies for the academic atmosphere construction in universities, the high awareness and the importance attached to it, will directly affect its effectiveness. In addition, the position of these administrators in academic atmosphere construction will also influence its development and implementation.

Stability of the Subject: The subject of academic atmosphere in universities is relatively fixed comprising of Managers, teachers and students. These are also the core and key components which enhance its competitiveness. Based on this, the strategic objectives of the academic atmosphere are set and then the development strategic planning of university is completed.

Group: Managers, teachers and students play a major role in the academic atmosphere construction, strengthen it by multiple approaches, and help to achieve good results. The academic atmosphere of the teachers and students influence, promote and develop interactively. Different subjects collectively play their respective synergic roles in the process of academic atmosphere construction. 


\subsection{The Relationship between IT Governance and Academic Atmosphere Management}

IT governance is to build an information-based decision-making system and organizational structure that takes into account the interests of all the relevant parties. Its basic approach involves performance evaluation and the risk management, and drives consensus between the application of informationization and the organization's strategic goals as the fundamental principle to create value for the organization. Among them, strategic coordination, value output, resource management, risk management, and performance evaluation are the main areas of concern for IT governance. As the source of IT governance, corporate governance has played a significant role in the development of enterprise informationization. Similarly, the introduction of IT governance in university academic atmosphere construction is very effective for the development of universities. Academic atmosphere governance in the university is the process of integrating academic atmosphere construction, organizational structure, operating processes and daily management of the university. The depth of its integration continues to advance with the passage of time and the development of technology.

Both the governance and management can be viewed as a hierarchical system, with authority and responsibilities delegated from the top to bottom for effective execution through supervision to ensure proper authorization. The authorization is the key principle in the governance. The core part is to ensure that the right persons with appropriate authority are placed in the right management structure to build an effective management institution according to the needs of the governance.

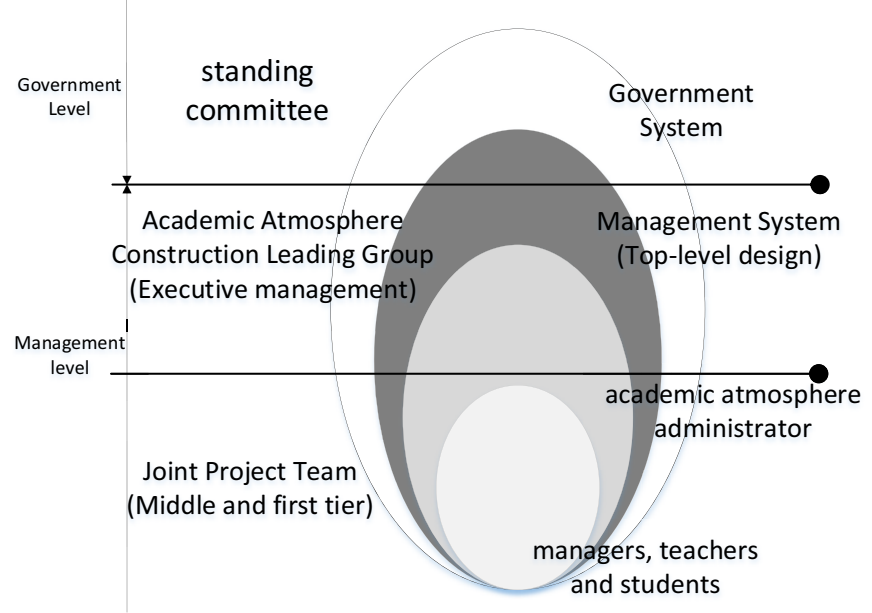

Figure 1. Nesting model of academic atmosphere governance and management relationship.

However, mere governance is not management. The management scope and authority need to be clearly separated. The Standing Committee (Board of Directors) is responsible for setting long term strategic goals whereas, the middle level is responsible for formulating the performance indicators. The relationship between the governance and management is shown in Figure 1. The governance system is responsible for formulating the strategies to ensure effective utilization of resources. But the success of academic atmosphere construction relies heavily on the management system of the entire organization. The top-level personnel may participate in some 
management processes, for example, designing school-wide governance actions. The management system manages the entire organization within the governance framework. The leading group (executive management) of academic atmosphere construction is responsible for creating and maintaining the goals determined by the governance system. At the same time, it also provides a guarantee for the governance system, so that all the types of resources are effectively used. The middle and the front-line staff from different departments are responsible for the proper execution of each item in terms of quantity and quality. As regards specific management, it is accomplished and executed through three relevant key elements namely, Principals, Operating Departments and Institutes, and Joint Project Team as shown in Figure 2.

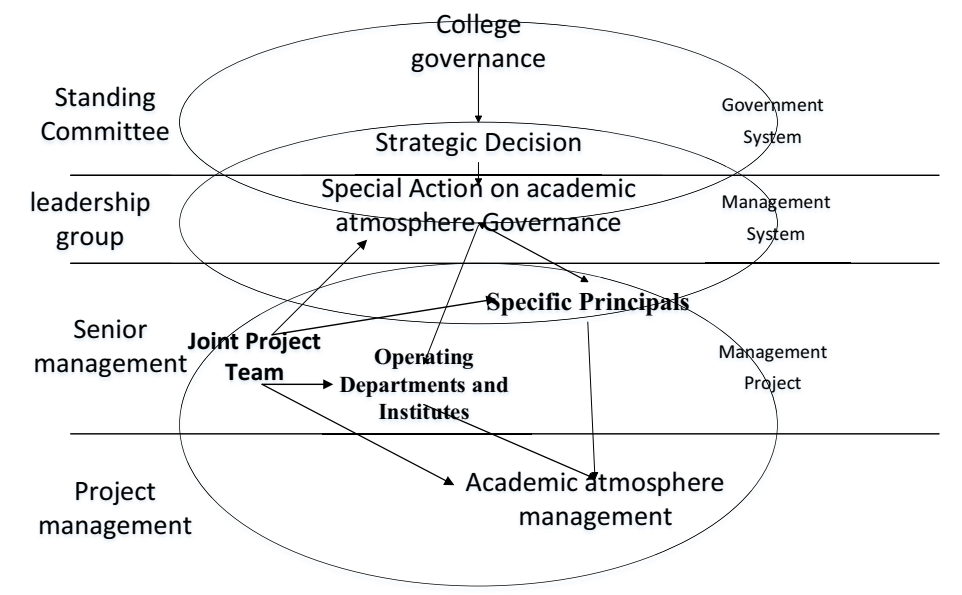

Figure 2. The Relationship between IT Governance and Academic Atmosphere Management

Specific Principals: It can be envisaged as a temporary institution established within the framework of a permanent institution. It does not have ready-made means to link to the entire organizational structure. Each connection must be "newly" created, and the specific principals in charge of academic atmosphere need to play a key role in this process. Ordinary departments must meet the governance requirements through established methods. But these methods however, do not exist in the temporary institutions. In order to meet the governance requirements, the management must ensure coordination between permanent and temporary institutions. Therefore, a specific principal in charge of the academic atmosphere is the key link to support good governance. These principals are responsible for all the activities in the entire life cycle namely, determine the business needs, establish specific key strategies, set definite specific project, negotiate goals, determine specific success standards, and continuously monitor the operating environment and benefits.

Operating Departments and Institutes: This in fact, is an important link which ensures the successful implementation of the university strategies. At the same time, it is also the core entity that connects the main body of the academic atmosphere. It supports the overall process of academic atmosphere governance by balancing workload, ensuring the reliability of information used for decision-making, and identifying future uncertainties. In short, as a part of academic atmosphere governance, the functions of operating departments and schools include the collection and verification of resource 
availability, crafting policies, procedures, methods and standards to formulate and implement effective decisions, ongoing monitoring and generating innovative ideas in governance.

Joint Project Team: The unprecedent management environment growth for specific academic atmosphere action necessitates joint project team to undertake multiple projects tasks. Every member of the project team needs to have the ability to manage a single project while coordinating multiple specific projects. They need to acquire multidisciplinary knowledge and skills in project management, standardized operations and maintenance. They focus mainly on synchronization, teamwork and inculcate team spirit to obtain higher quality information to improve efficiency and balance the competitive needs of various projects thus, meeting the structure of the overall governance framework.

\section{Conclusion}

This paper explores a set of overall solutions for academic atmosphere governance based on IT governance in practice. This idea is more suitable for the governance thinking of operating informationization and management datamization from the perspective of big data. As compared to the traditional academic atmosphere governance plans, this effect is more significant and is essentially, an ideal alternative plan. Subsequently, the school administrators can establish a more focused and longterm effective academic atmosphere governance system through exploration and practice of the program in university for ongoing improvements. In the long run, it will make a virtuous cycle between the teaching operation and teaching construction in the universities, and better adapt to the requirements of rapid development education informationization in the era of big data.

\section{References}

[1] Wendy Kopp, Steven Farr. A Chance to Make History: What Works and What Doesn't in Providing an Excellent for All. 2013,p.23-5.

[2] Wang enjuan. Research on the Present Situation and Evaluation System of Contemporary College Students' Style of Study. Statistics and Management, 2017 ; (11):22-2.

[3] Zhang Diping, Lai Yuefu. Research on the Comprehensive Evaluation of the Construction of College Students' Academic Atmosphere. University Education, 2017; (7):191-3.

[4] Zong Yuhong. Research on the Comprehensive Evaluation of SRU College Style Construction. Xi'an Polytechnic University, 2018,p.35-6.

[5] HUI Zhi-bing. Several Strategies for Strengthening the Study Style of University Students. Education Teaching Forum, 2019;5(1):224-2.

[6] YU Chang. Innovation of the style of study in universities from the perspective ofThree Complete Education: a study of science students.Journal of zhejiang university of technology( social science) ,2020;19(1):105-6.

[7] Yu-hua CHEN Tao JIN Kai CUI Jing-yi. Research and Practice of Academic Atmosphere Construction in Colleges and Universities from the Persspective of "Three Whole Education"FAN. Education Teaching Forum, 2020;(26):25-2. 